\title{
Outpatient Waiting Times: Indicators of Hospital Performance?
}

Maj AMJ Croft

MA, MSc, MBBS, MIL, DMCC, MFPHM, RAMC

Consultant in Public Health Medicine

Brig P Lynch

$M D, F R C P$, late RAMC

Director of Personnel and Services

Mr JS Smellie

BA (Hons)

Assistant Director of Corporate Planning

Headquarters Defence Secondary Care Agency, Ministry of Defence, St Giles' Court, London, WC2H 8LD

\section{Lt Col CJ Dickinson}

MSc, RAMC

Military Executive Officer

Ministry of Defence Hospital Unit, Frimley Park Hospital, Portsmouth Road, Frimley, Camberley, Surrey, GU16 5UJ

SUMMARY: We monitored outpatient waiting times at UK military hospitals over an 18-month period (September 1996 - March 1998). The highest mean waiting times for Consultant appointment were in urology (19 weeks) and orthopaedics (18 weeks). The lowest mean waiting times were in psychiatry (3 weeks), ENT surgery (5 weeks) and 8 rheumatology (6 weeks). Waiting times for surgical specialties were around $50 \%$ higher than for medical specialties. The inter-hospital variability in waiting times was $260 \%$. Military waiting list initiatives were introduced in 4 key specialties, but the majority of these initiatives only had a temporary impact in reducing outpatient waiting times Waiting times reflect the accessibility of a hospital's services, and are a crude but easily measured indicator of one aspect of patient care. With a military population base, outpatient waiting times should be reduced to the lowest practicable level. The keys to achieving a long-term reduction in waiting times are proper staffing levels and the efficient management of clinics.

\section{Introduction}

Although the National Health Service (NHS) has been in existence for 50 years, it is only within the past decade that the government has begun to routinely collect and publish data on comparative hospital performance. The driving force in this change has been the quest for efficiency in the face of spiralling healthcare costs (1). A contributory factor was the introduction of market forces into healthcare, which from the outset presupposed that purchasers would have appropriate data on which to judge the relative business performance of their potential providers $(2,3)$. The advent of electronic information management systems also made it possible for the first time to collect healthcare data reliably from many sites, and to analyse and publish those data swiftly $(4,5)$.

In 1994 the Department of Health started to collect statistics on how long people in England waited for their first outpatient appointment in the NHS, after referral by the general practitioner (GP). The first published data on this were for the quarter ending in September 1994 (6). It was reported that $83 \%$ of patients waited under 13 weeks and $96 \%$ under 26 weeks for their first appointment. A national standard issued in 1995 set a target which specified that:

" $90 \%$ of patients should be seen within 13 weeks, and all should be seen within 26 weeks" (7).

Since 1995 the outpatient waiting times for all NHS trust hospitals have been published quarterly, and the 13- and 26 - week watersheds have been used as benchmarks by which the relative service accessibility of each hospital has been judged.

During 1996 a number of new agencies were created in the Surgeon General's Department, one of these agencies being the Defence Secondary Care Agency (DSCA). In accordance with modern business practice, the agencies were to publish their mutually agreed business objectives, and to work to performance targets (or "key targets") derived from those objectives and reviewed annually (8).

As from September 1996, data on outpatient waiting times for Service personnel were routinely collected from all DSCA hospitals in the UK. Armed Forces GPs were informed about current waiting times through a DSCA bulletin sent directly to medical centres. GPs were reminded of their right to refer military patients to any DSCA site, and were actively encouraged to use those 
hospitals with the shortest waiting times.

Early in the monitoring process it was found that some outpatient waiting times were unacceptably high. This was due to long waiting lists inherited from the early closure of Army and RAF hospitals during 1995-96. A series of waiting list initiatives was therefore set in place at various UK hospitals, both military and civilian, with the aim of reducing outpatient waiting times for those Armed Forces personnel being referred to overloaded specialties. These waiting list initiatives are summarised in Table 1.

In the light of continuing Ministerial concerns about long outpatient waiting times at DSCA hospitals, one of the agency's key targets for 1997-98 was:

"To ensure that $50 \%$ of Service patients are offered a first outpatient appointment within 4 weeks of a referral, and 90\% within 13 weeks" (9).

The aim of this paper is to review trends in waiting times for military outpatients since September 1996, and to assess the impact on waiting times of the various waiting list initiatives.

\section{Methods}

We extracted outpatient waiting time data from the statistical return MANINFO/1, which is reported electronically at the start of each month to DSCA headquarters from each of its five UK sites. These are: the
Royal Hospital Haslar, the Duchess of Kent Hospital Catterick, and Ministry of Defence Hospital Units (MDHUs) at Derriford, Frimley and Peterborough.

For the purposes of the MANINFO/1 return, the outpatient waiting time for a particular specialty at a given음. hospital is defined as:

"The time in weeks which will elapse before a Service patient referred routinely in the first week of the reporting month is seen in the hospital's Outpatients Department."

This definition differs very slightly from that used by the NHS (10).

To facilitate comparisons between hospitals, and across different specialties, we calculated an aggregated monthlyo "weighted mean" for each hospital. We used totalConsultant numbers in that hospital or specialty as a proxy of activity, so as to assign to each reported figure a greater $\vec{\omega}$ or lesser weight. This was to ensure that, for example, as general orthopaedics clinic with a very low waiting times but just one Consultant carried only a third as much weight in the aggregated specialty mean as an orthopaedics service $\vec{A}$ in a different hospital with a higher outpatients waiting time and staffed by three Consultants.

We analysed the data using the Excel spreadsheet featured of Microsoft Office software package, and charted the calculated means at Figures 1-3. For simplicity, and because small numbers of patients and staff had resultedōn

Table 1

Waiting list initiatives for Armed Forces outpatients 1996-98

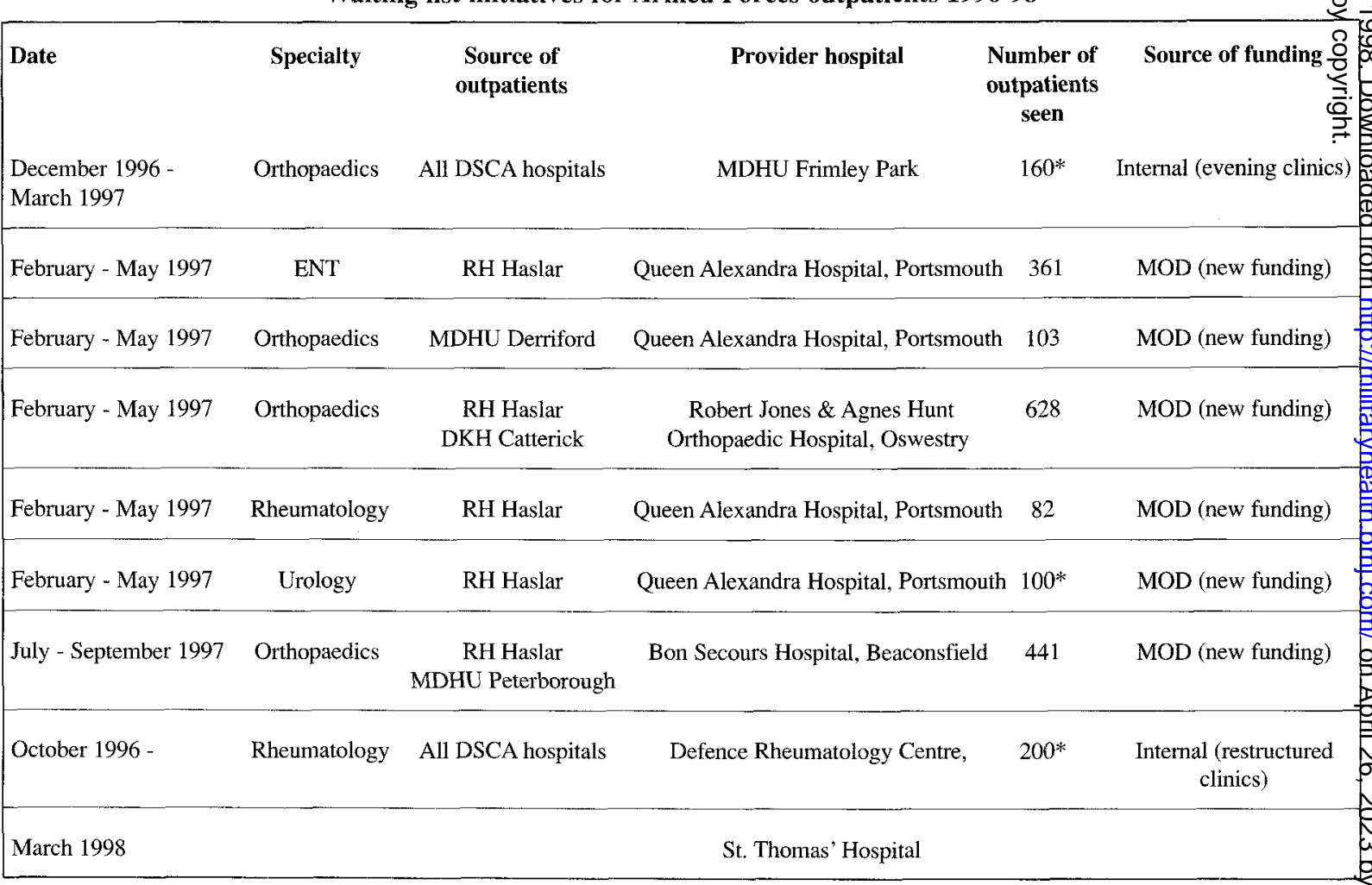




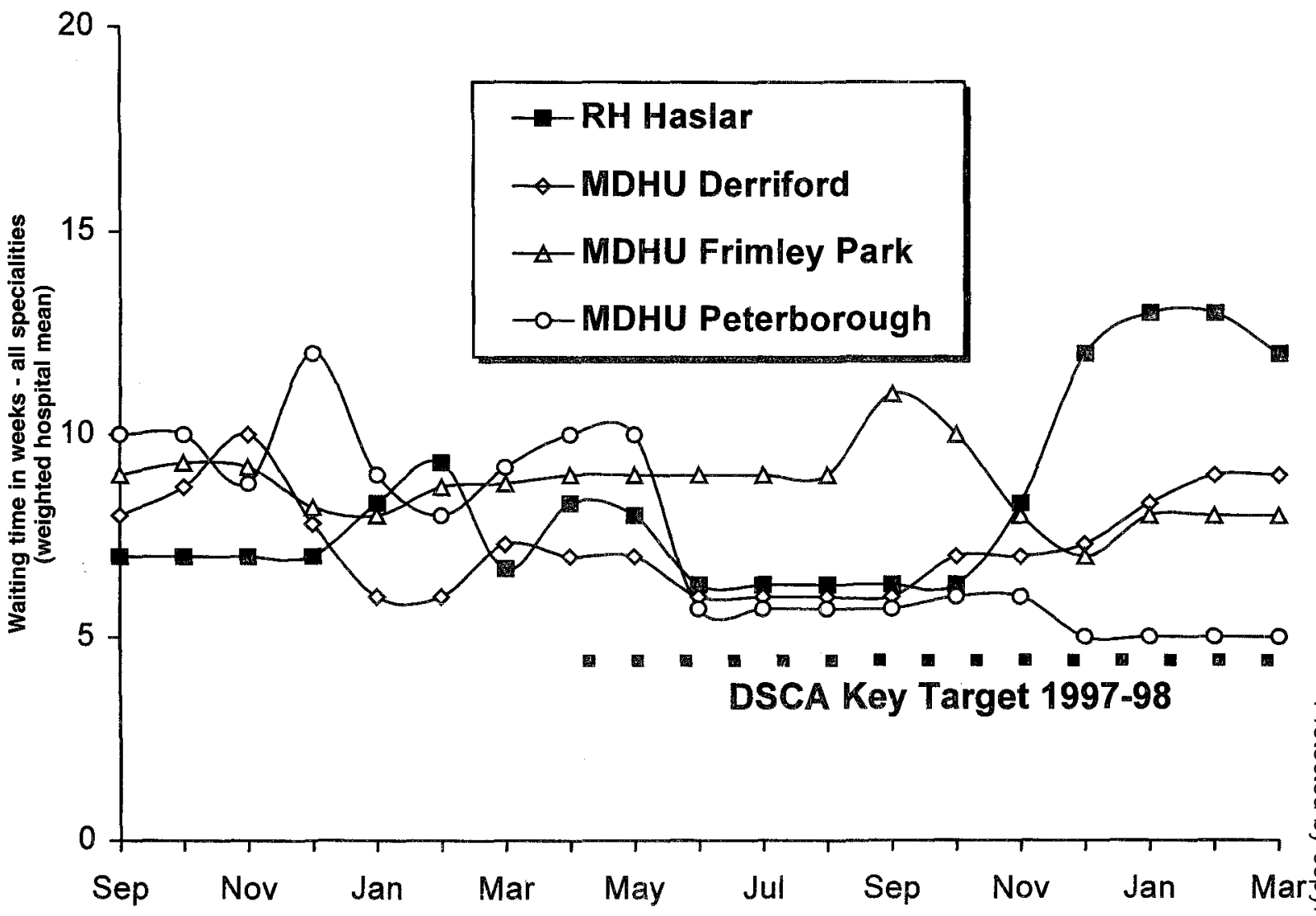

1996

1997

Fig 1. Outpatient waiting times (all specialties) at DSCA hospitals 1996-98

erratic fluctuations in waiting times, we have not charted the data from the Duchess of Kent Hospital, Catterick.

\section{Results}

Aggregated waiting times (all specialties) at DSCA hospitals

Figure 1 shows time-trends in aggregated waiting times for military outpatients, by DSCA hospital. The highest outpatient waiting times were at Haslar in the early months of 1998, when the aggregated all-specialty mean reached thirteen weeks. The lowest waiting times were at MDHU Peterborough in the same period, when they were down to five weeks. This represents an inter-hospital difference of $260 \%$.

There was marked seasonal variation in waiting times at most hospitals, with most sites experiencing a temporary rise in their aggregated mean waiting times during the Christmas months, and a similar temporary rise in the summer.

Aggregated waiting times in selected medical specialties

Figure 2 shows that there were very striking fluctuations in outpatient waiting times in the four medical specialties charted, with no obvious seasonality. This reflects the fact that there are fewer military physicians than there are surgeons, so that the removal from the peacetime pool of even one physician (e.g. through exercise, deployment, illness or retirement) can lead to an immediate rise in the mean outpatient waiting time for that specialty.

Rheumatology benefited from two successive waiting list initiatives during this period. Waiting times fell rapidly, but (in the case of the first initiative) rose again once the initiative had been discontinued.

Aggregated waiting times in selected surgical specialties

Figure 3 shows that in the surgical specialties the proportionately higher number of military Consultants had the effect of damping down short-term fluctuations caused by seasonal theatre closures or by individual Consultant postings.

Overall, surgical waiting times for routine outpatient appointments were roughly $50 \%$ higher than medical waiting times. Orthopaedics and urology had particularly long waiting times, and waiting list initiatives in these two 


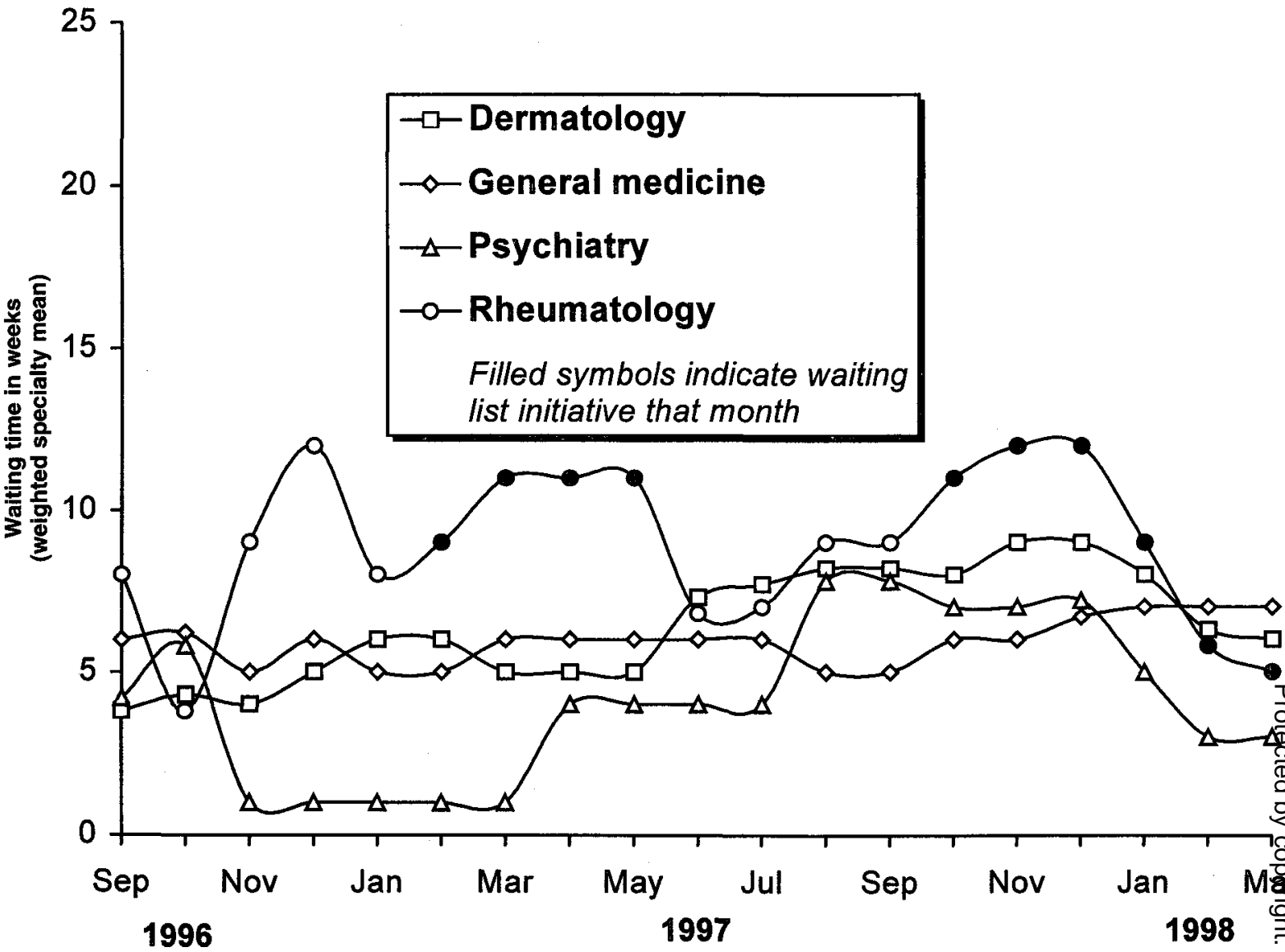

Fig 2. Outpatient waiting times for Service personnel. Selected medical specialties 1996-98

areas had only a temporary impact in reducing military outpatients' lengths of wait.

One apparent success was in the field of ear, nose and throat (ENT) surgery. At the start of the survey, the aggregated mean waiting time for ENT surgery was around fifteen weeks. There was one ENT waiting list initiative between February - May 1997. By early 1998 the mean wait had fallen to five weeks.

\section{Discussion}

This was the first-ever exercise in monitoring outpatient waiting times in military hospitals. The waiting times for Service hospitals were not routinely reported at any time in the past, and so validated historical comparisons are not possible. It was surprising to find that there was such marked inter-hospital variability in waiting times, and we must infer that because of their geographical location some UK-based servicemen and women who need a military Consultant opinion are disadvantaged relative to others.

Because DSCA waiting times are reported as a continuous variable, rather than according to arbitrary 13and 26- week watersheds, a direct comparison with NHS waiting times is not possible. However there is muchō scepticism in managerial circles as regards the validity of the NHS reporting system for waiting times (11-14), and we believe that the DSCA method has the advantage of greater transparency.

Implications of monitoring for organisation of the services

The findings of this paper should not be used to infero that no DSCA hospital achieved its 1997-98 key target for outpatient waiting times. We are reporting here on prospective snapshot of all those military outpatients 3 . referred (some of whom would ultimately be non- attenders). The DSCA key target, on the other hand, is measured as a proportion of those patients who wereo actually seen. The key target has a lower and an upper tolerance limit. In the great majority of specialties, once non-attenders were removed from the equation, most military outpatients in DSCA hospitals were seen welp within their upper limit of 13 weeks (by contrast the NHSO upper limit is 26 weeks). This would certainly have beentw

true of all cases of urgent clinical need.
Because military outpatient appointments are stillb 


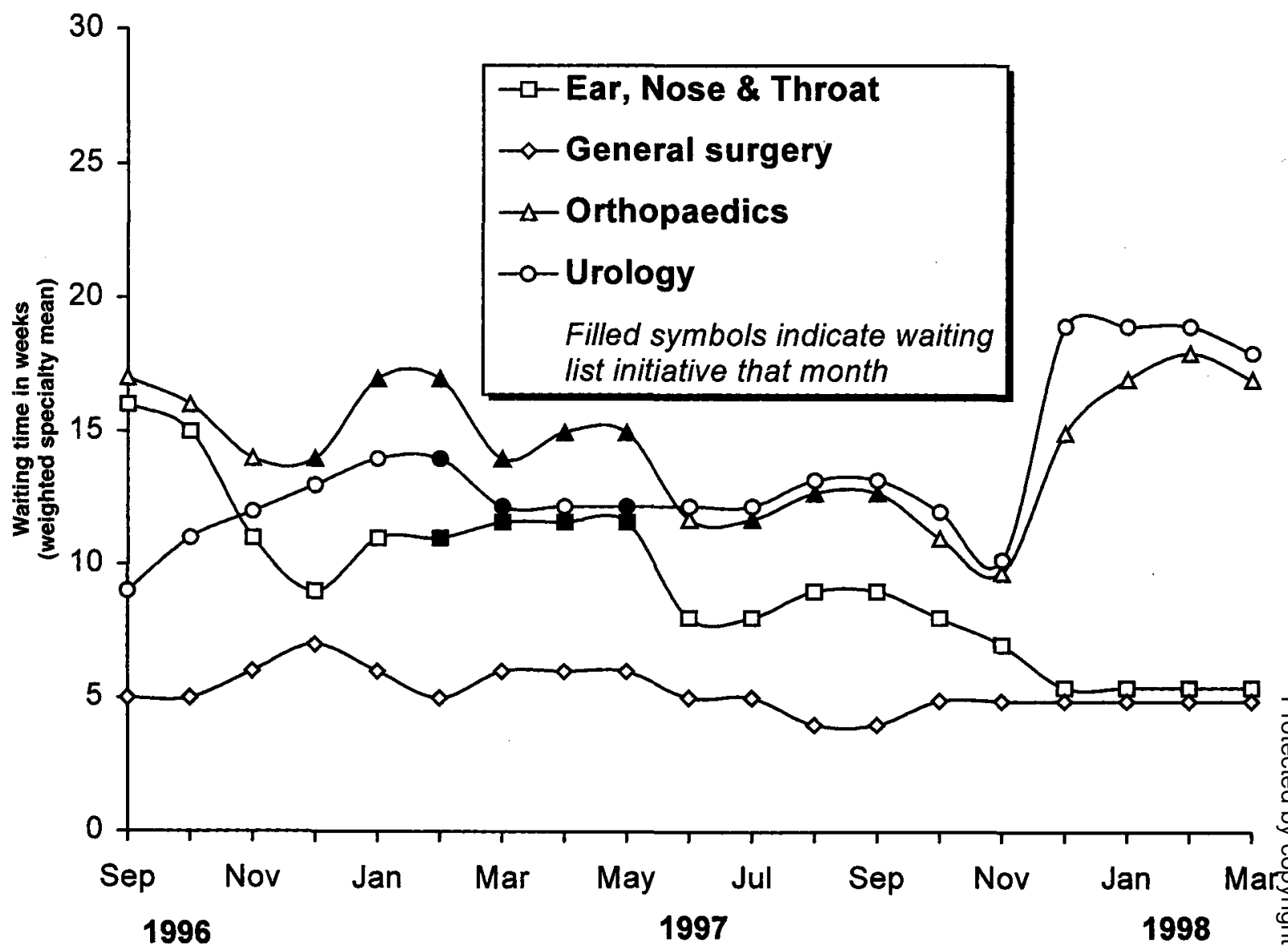

Fig 3. Outpatient waiting times for Service personnel. Selected surgical specialties 1996-98

mostly made through the time-honoured medium of a GP letter to the Consultant, delivered usually by the military postal service, we believe there is a "bureaucracy lag" of 3-5 weeks in the time it takes to obtain a routine Consultant appointment, even under conditions of ideal clinic staffing. It is hoped in time to introduce in all DSCA hospitals an electronic system for booking outpatients appointments. A system of making clinic appointments by fax has been piloted in the past year at MDHU Frimley Park, with some success. In addition, a "fast-track" booking system for personnel at very short notice to deploy was introduced in June 1997 at all DSCA sites, and it was found possible to guarantee a Consultant opinion for selected military outpatients within three working days.

The continuous monitoring and regular publication of outpatient waiting times has exposed the acute staffing shortages that currently exist in some specialty areas in the - Defence hospital service. This has brought the manning shortfalls to the attention of Ministers, and has given added impetus to efforts to recruit more actively into these specialties (15). The organisation of every DSCA specialty is now subject to close scrutiny through a continuous programme of specialty reviews, involving all levels of management.

The observation that waiting times in orthopaedics and urology rose swiftly once the waiting list initiatives had been discontinued is in line with NHS experience that such initiatives in isolation are inefficient, and do not promote long-term improvements in services (16-18). Only ENT waiting times remained low after a DSCA waiting list initiative, and this was due not so much to the initiative per $s e$ as to concurrent measures to reduce the large number of inappropriate audiological referrals from primary care, a legacy from pre-DSCA procedures.

\section{Implications of monitoring for quality of clinical care}

Long waiting times are invariably counter-productive to the good management of the patient's medical complaint (19). For the patient, the wait can be an anxious time often accompanied by disability or pain. For the clinician, treatment may become more difficult if the condition worsens. It has also been shown that hospital nonattendance rates are higher if the waiting time is long $(20,21)$. 
We accept that simply recording the mean length of outpatient wait may not directly correlate with the quality of clinical care that the patient eventually receives, and that indeed there may be an inverse correlation (22). Nevertheless the outpatient waiting time is an easy parameter to measure, and for many conditions it is unquestionably important that the patient be seen quickly, in order to prevent an avoidable deterioration in health. In a military setting ill-health can preclude deployment and jeopardise career prospects, and so swift treatment is particularly desirable for operational and personnel management reasons.

\section{Hospital waiting times and general practitioners}

Although we did not formally survey Armed Forces GPs on their perceptions of the DSCA monthly waiting times bulletin, there was anecdotal evidence during this period that the bulletin was well received.

A recent postal survey of practices in Avon Health Authority found that GPs place a high priority on receiving waiting time information from central sources, probably because of the direct impact of this information on patient care (23). A randomised controlled trial of practices in the west Midlands, not since replicated, found that providing standardised waiting time information led to some changes in patient referral patterns (24). The same trial concluded that it was probably not necessary to send waiting time information to GPs as often as once a month. In the light of this research finding, the DSCA waiting times bulletin is now sent out to Armed Forces GPs every two months.

\section{Conclusions}

Outpatient waiting times are a crude indicator of one aspect of hospital performance. They reflect the accessibility of the hospital service, and it can be argued that this is important where (as in the Armed Forces) the patient base is a highly trained, rapidly deployable workforce, in which the very prompt treatment of any illness is desirable. The military hospital service must continue to strive to reduce its waiting times to the lowest practicable levels, in deference to political sensitivities and to give maximum benefit to our military outpatients.

\section{Acknowledgments}

We thank Simon Leigh, Paul Court and Sue Prescott for collating the statistics on which this paper is based, and hospital information staff for their monthly reporting of the raw data.

\section{REFERENCES}

1. WEALE A. Rationing health care. BMJ 1998; 316: 410.

2. Secretary of State for Health. Working for patients. Command 555. London: HMSO, 1989.

3. Figueras J, Roberts JA, SANDERSON CF. Contracting, planning, competition and efficiency. In: Malek M, Vacani P, Rasquinha J, Davey P, eds.
Managerial issues in the reformed NHS. Chichester: John Wiley \& Sons, 1993: 223-226.

4. BLACK N. Information please - and quick. BMJ 1989; 298: 586-587.

5. Information Management Group, NHS Management Executive. An information management and technology strategy for the NHS in England. London: Department of Health, 1992.

6. Department of Health. Waiting times for first outpatient appointments in England: quarter ended 30 September 1994. Statistical bulletin 1995/3. London: Department of Health, 1995.

7. Department of Health. Press release 95/25. London: Department of Health, 1995.

8. SMITH R. Introducing the agencies. The Defence Secondary Care Agency - a new structure for the delivery of high quality patient care. JR Nav Med Serv 1996; 82: 45-47.

9. Defence Secondary Care Agency. Business plan financial year 1997-98. London: Ministry of Defence, 1997.

10. Information Management Group, NHS Management Executive. Data manual Version 4.0. London: Department of Health, 1996.

11. Radical Statistics Health Group. NHS "indicators of success": what do they tell us? BMJ 1995; 310: 10450 1050.

12. DiCKsON N. League tables; use for patients. Qudâ Health Care 1995; 4: 1.

13. Goldstein H, SPIEGelHalter DJ. League tables and their limitations: statistical issues in comparisons of institutional performance. JR Statist Soc A 1996; 159. 385-443.

14. MCKeE M, RAFFerty A, AiKen L. Measuring hospita performance: are we asking the right questions? $J R$ Soc Med 1997; 90: 187-191.

15. BeECHAM L. Minister admits defence medicine is a sorry mess. BMJ 1997; 315: 1240.

16. Mrlls RP, Heaton JM. Waiting list initiatives: crisis management or targeting of resources? JR Soc Med 1991; 84: 405-407.

17. UMEH HN, REece-SMith H, FABer RG, Galland RB. Impact of a waiting list initiative on a general surgical waiting list. Ann R Coll Surg Engl 1994; 76 (suppl): 4-7.

18. Clinical Standards Advisory Group, NHS Management Executive. District elective surgery. Access to and availability of services. London: The Stationery Office, 1996.

19. Department of Health. NHS waiting times. Guidelines for good administrative practice. Leeds: NHS Executive, 1996.

20. Bowman RJC, BennetT HGB, Houston CA, AITCHISON TC, DutTon GN. Waiting times for and attendance at paediatric ophthalmology outpatient appointments. BMJ 1996; 313: 1244.

21. Anonymous. Shortening waiting times helps reduce no-shows. Inside Ambulatory Care 1996; 2: 1-3. 
22. HART M. Incorporating outpatient perceptions into definitions of quality. J Adv Nurs 1996; 24: 12341240.

23. SHEPHERD M, Young P. What GPs want from the internet: the findings of Avon Health Authority. British Journal of Health Care Management 1998; 4: 40-42.
24. French JA, Stevenson CH, Eglinton J, Bailey JE. Effect of information about waiting lists on referral patterns of general practitioners. Br J Gen Pract 1990; 40: $186-189$. 